\title{
Perspectives on Mental Wellness in Child and Youth Care Education
}

\author{
Louise McDonald \\ BCYC, MacEwan University, Alberta, Canada \\ Nicole Pawlick \\ BCYC, MacEwan University, Alberta, Canada \\ Gerard Bellefeuille \\ Professor, Department of Child and Youth Care \\ MacEwan University, Alberta, Canada
}

\begin{abstract}
This course-based research project is conducted in a qualitative interpretive paradigm. The purpose of the inquiry is to gain insight into how students interpret their own subjective experiences and understanding of the impact that the undergraduate child and youth care program at MacEwan University has had on their mental wellness. A purposive sample of four child and youth care students was selected. Data was collected through the use of a semi-structured focus group and a reflective arts-based activity. The data was analysed using Braun and Clarke's approach to thematic analysis which resulted in the identification of six themes. These include: a) safe and supportive learning environment, b) enhanced understanding, c) genuine student-professor relationship, d) seeing mental health as a strength, e) the healing power of creativity and play, and f) transformational nature of child and youth care education.
\end{abstract}

Keywords: arts-based methods, child and youth care, course-based research, mental wellness, qualitative inquiry

\section{INTRODUCTION}

Students who have graduated from the child and youth care (CYC) program at MacEwan University can tell you that throughout their educational experience there were times when they felt emotionally drained, overwhelmed, and fatigued due to the program's emphasis on having students self-disclose and engage in conscious self-awareness. There is no uncertainty that self-awareness is an essential element to prepare students to become effective and competent CYC practitioners (Bellefeuille \& Jamieson, 2008; Fewster, 1990; Garfat, 2008; Krueger, 2000; Maier, 1979; Ricks, 2003). However, knowing oneself deeply and honestly is no easy task. Cultivating self-awareness is often a stressful, agonizing, and time-consuming process. It involves developing the insights necessary to recognize and understand the differences between who one thinks one is and who he or she actually is. For example, EckrothBucher (2010) defines the concept this way: "Self-awareness involves the cerebral exercise of introspection. This attribute reflects the cognitive exploration of our own thoughts, feelings, beliefs, values, behaviors, and the feedback from others" (p. 297). In terms of relationalcentred CYC practice, being present to the other (a client) is impossible without being present to the self (practitioner) (Ricks 1898, 2003). As Ricks explains, "to know about the client requires being aware of self since the client only exists out of one's self experience of the other person" (p. 35) and that "without self there is no other" (2001, para. 1). In keeping with this tenet, exercising self-awareness is a precondition for being ethical and competent in one's 
work with children and families. In seeking to achieve self-awareness, the classroom becomes a therapeutic milieu that demands a high degree of openness and vulnerability, a condition in which CYC students are encouraged to re-examine their beliefs, biases, and prejudices through self-reflection, introspection, and self-disclosure. While the faculty do their best to create a safe and supportive classroom environment, for some students the stress can exacerbate preexisting mental health conditions or cause new conditions to emerge. As fourth-year students who feel our own mental wellness has benefited greatly from the CYC program, this coursebased research project represents a great opportunity to explore the experiences of other fourth-year CYC students and graduates of the program and their perception of the impact of the CYC program on their mental well-being.

\section{UNDERGRADUATE COURSE-BASED RESEARCH: A PEDAGOGICAL TOOL TO FOSTER CRITICALITY, REFLECTIVITY, AND PRAXIS}

The Bachelor of Child and Youth Care program at MacEwan University is continuously searching for new pedagogical approaches to foster criticality, reflectivity, and praxis as integral components of the overall student educational experience. As such, the design and implementation of a course-based approach, in contrast with the traditional didactic approach to research-methods instruction, offers fourth-year undergraduate students the opportunity to master introductory research skills by conceptualizing, designing, administering, and showcasing small minimum-risk research projects under the guidance and supervision of the course instructor-commonly, a professor with an extensive background in research and teaching.

Use of course-based research in higher education has soared in recent years (Allyn, 2013; Bellefeuille, Ekdahl, Kent, \& Kluczny, 2014; Harrison, Dunbar, Ratmansky, Boyd, \& Lopatto, 2010). The benefits derived from a course-based approach to teaching research methods for child and youth care students are significant. First, there is value in providing students with authentic learning experiences that enhance the transfer of knowledge obtained in formal education to practice. Previous students have reported that their engagement in course-based research has enabled them to expand their depth of scientific knowledge by adopting new methods of creative inquiry. Second, course-based research offers students the opportunity to work with instructors in a relationship characterized by mentoring, which results in a greater number of students who express interest in advancing to graduate studies. Third, the results of course-based research can sometimes be published in peer-reviewed journals and online open-access portals and, thus, contribute to the discipline's knowledge base.

Ethical approval required to enable students to conduct course-based research projects is granted to the course instructor by the university's research ethics board (REB). Student research groups are then required to complete an REB application form for each course-based research project undertaken in the class, which is then reviewed by the course instructor and a sub-REB committee to ensure each project is completed and in compliance with the ethics review requirements of the university.

\section{RESEARCH PARADIGM}

This course-based research project, under the umbrella of the interpretive paradigm, is qualitative in nature. It seeks to gain insight into the interpretations that participants have of their mental wellness as a direct impact of their undergraduate (CYC) program experience at MacEwan University. The interpretive paradigm represents the ontological and epistemological positions that underpin the formulation of the research question and the methodological framework employed. In the context of the interpretive paradigm, reality is regarded as subjective and is considered to be constructed socially through interactions and 
founded on the meaning people attach to it (Creswell, 2013; Patton, 2002). Thus, the notion of "truth" is understood to be an interpretation of phenomena that is dependent on context and is thus dynamic and evolving. Individuals are framed as interpreters of their experiences and creators of their realities (Creswell, 2013; Schwandt, 2000). In contrast to the need for researcher detachment that is central to a quantitative paradigm, the interpretive approach posits that there is no value-free research. The interpretive approach frames researchers' values as inherent to and influential in all phases of the research process and as, effectively, inseparable from the inquiry (Schwandt, 2000). In other words, the researcher and the participant are considered to be interrelated, and this relationship serves to expand and deepen the researcher's understanding of the participant's experience.

\section{Sampling Strategy}

A purposive criterion sampling strategy was utilized to recruit participants for this coursebased research project. Purposive sampling is an identification and recruitment method widely used in qualitative research to obtain information-rich data through a transparent system of selecting participants (Patton, 2002). This strategy enabled us to purposefully select individuals who could provide the necessary data and contribute to our understanding of the phenomenon under investigation. As Stake (1994) suggests, if qualitative research requires the selection of cases, then "nothing is more important than making a proper selection of cases" (p. 243). We drew our sample from a group of CYC students who have been involved in a writing project about their mental wellness in relation to their CYC educational experience.

\section{Statement of Research Question}

Do CYC students at MacEwan University view the CYC program as supportive of their mental wellness? If so, how?

\section{Data Collection}

The data for this course-based research project were collected through the use of a semistructured focus group and an expressive arts-based activity.

\section{Semi-structured focus group}

A focus group was chosen as the primary means of data collection because this tool commonly yields rich data characterized by a high level of complexity when used to explore participants' subjective experiences (Stewart, Shamdasani, \& Rook, 2007). Krueger (1994) defines a focus group as "a carefully planned discussion, designed to obtain perceptions on a defined area of interest in a permissive, non-threatening environment" (p. 6). In this course-based research project, the focus group was exploratory in nature. After participants introduced themselves to the group, semi-structured questions were used to encourage conversation within the group and transition questions were used to introduce participants to a broad view of the selected topic.

\section{Reflective arts-based activity}

Arts-based research methodologies use artistic forms of expression to introduce a creative process in one or more phases of a research process. The goal of these methodologies is to explore, understand, represent, and challenge human experiences (McNiff, 2007). Artistic forms include one or more of the following: poetry, drawing, sculpting, music, visual art, drama, and dance. These forms have been used successfully in a variety of research disciplines (Hannula, Suoranta, \& Vandén, 2005; Leavy, 2009). 


\section{Data Analysis}

A central component of the research process is the selection of an appropriate data analysis method. As Guest, MacQueen, and Namey (2012) explain, "approaches to qualitative data collection and analysis are numerous, representing a diverse range of epistemological, theoretical, and disciplinary perspectives" (p. 3). The six steps prescribed by Braun and Clark (2006) were selected as the optimal method of analysis because they provided a good fit for the primary research purpose, which is to gain insight into how students interpret their own subjective experiences and understanding of the impact of MacEwan University's undergraduate CYC program on their mental wellness.

\section{Findings}

The thematic analysis resulted in the identification of six themes. These included: a) safe and supportive learning environment, b) enhanced understanding, c) genuine student-professor relationship, d) seeing mental health as a strength, e) the healing power of creativity and play, and f) the transformational nature of CYC education.

\section{Safe and supportive learning environment}

Participants talked about how the interactive and relational emphasis of the classroom milieu encouraged them in a variety of ways to openly share their personal experiences without fear of rejection by their classmates. They discussed that they felt safe and protected by their professors when they chose to share about their mental health symptoms, struggles, treatments, or diagnoses. For example, one participant said, "I was encouraged to talk openly about my mental health." Another participant noted, "I was shocked that they were interested to know more about me." Some of the participants explained that their relationships with the professors created a sense of equality in and out of the classroom. Participants' comments included that "they build on your strengths." "they actually want you to succeed," and "they actually care about you."

\section{Enhanced understanding}

Participants felt that mental health self-disclosures in the classroom helped their classmates to better understand the effects of having a mental health disorder and what living with such a disorder can entail. Participants felt that such disclosures helped their classmates to comprehend why other classmates acted in certain ways and made them more empathetic or aware. For example, one participant said, "it created a sense of community in the program, like being part of something." Another stated, "the classroom felt like a place I could trust." Participants also noted that many classmates reacted to mental health self-disclosures with a new-found respect for the individual in his or her ability to live successfully with mental health concerns. Expressions of respect included, "I recognized others were there to support me and I reciprocated that" and "we [fellow students] became friends through shared vulnerable experiences."

\section{Genuine student-professor relationship}

Many of the participants talked about how professors fulfilled many roles beyond that of just a teacher. One participant stated of her professors, "they actually want you to succeed" and "they actually care about you" as compared to other programs. For many participants, professors were their main source of personal support in everything school related and even provided support outside of school. Related comments included, "they were willing to meet me outside of class time for personal reasons" and "they provided a safe-zone for us." Participants spoke about how their professors had a big impact on the them and made them feel supported, understood, and cared for. They observed that professors taught them how to care and truly do the work of 
a CYC worker. Participants talked about the longevity of the relationships and how support continued beyond graduation.

\section{Seeing mental health as a strength}

Many of the participants talked about how they felt that their mental health issues were a negative part of their lives prior to entering the CYC program. They described such issues using phrases like "it was a curse" and "I was forced to live with it." Most notably, participants referenced the strength-based philosophy of the program as having the greatest influence on their thinking. They discussed how the program made them analyze their mental health and their past experiences and begin to recognize the strength and resiliencies that it had given them. Some of the strengths that came from their mental health were the ability to relate to others and to see strengths in others with whom they work. Comments included, "I was able to use it as a strength," "I don't think I would have ever seen the benefits or the strengths of it (mental health) if it wasn't for this program," and, "this is my mental illness, and this is how I'm going to use that to work with my youth."

\section{The healing power of creativity and play}

Participants noted how the emphasis on experiential and arts-based approaches to teaching and learning were unlike their previous educational experiences. They cited how many of the assignments encouraged creativity, inspired their imagination, promoted critical thinking, and gave them new ways to express themselves, all of which they found therapeutic. Some of the participants' comments about the assignments included that "they encouraged creativity and play" and "they forced us to think outside the box", and participants liked "not necessarily being confined to a certain style of learning." As students progressed through the degree, however, they began to understand why the assignments were structured as they were and began to enjoy the freedom the assignments allowed. Participants mentioned that they believed assignments were structured freely because such freedom teaches students how to become adaptable within their work in the field and to begin to discover their professional identity. Participants shared how helpful it was to express their thoughts and feelings in creative ways that included painting, videos, poems, and music. The participants' creative pieces of art produced as part of their participation in this course-based research project reflected their self-confidence in expressing themselves openly.

\section{Transformational nature of child and youth care education}

Finally, many of the participants discussed the transformational nature of their CYC educational experience. They talked about the holistic view of CYC education that addresses the whole person by focusing on the relationship between the head, heart, and soul, and the interconnectedness of knowledge, theory, and practice. For example, one participant commented of this approach that "it gave us a platform to work with our mental health as a strategy." Participants talked about the large focus on self-exploration and identity, which is designed to help them become more aware of their biases and triggers and to learn how to deal with them. They also talked about the emphasis on self-care. For example, participants stated of the program, "they forced self-care, knowing what it means and knowing when to use it" and "they reminded us it is not selfish to address your own needs".

\section{DISCUSSION}

These findings present a description of undergraduate CYC student perspectives of the CYC program as supportive of their mental wellness. As a whole, the participants experienced a positive shift in their mental wellness as a result of their participation in the CYC undergraduate program at MacEwan University. They appreciated the genuine relationships that were forged with their professors and the creative, arts- and activity-based experiential teaching and learning approach that the CYC program offered. From our findings, it appears 
that hearing mental health self-disclosures in the classroom helped students to understand the effects of having a mental health condition and what living with such a condition can involve. Such disclosures also helped students to comprehend why their fellow classmates might behave a certain way. Finally, the findings demonstrate the power of a holistic approach to teaching and learning that promotes growth in all areas of the human experience: intellectual, emotional, social, and beyond.

\section{References}

Allen, J. P., \& Manning, N. (Eds.). (2007). From safety to affect regulation: Attachment from the vantage point of adolescence. New Directions in Child and Adolescent Development,117, 23-39.

Bellefeuille, G., Ekdahl, C., Kent, L., \& Kluczny, M. (2014). A course-based creative inquiry approach to teaching introductory research methods in Child and Youth Care undergraduate education. International Journal of Teaching and Education, 2(2), 1-9.

Bellefeuille, G., \& Jamieson, D. (2008). Relational-centred planning: A turn toward creative potential and possibilities. In G. Bellefeuille \& F. Ricks, (Eds.) Standing on the precipice: Inquiry into the creative potential of Child and Youth Care Practice (pp. 35-72). Edmonton, AB: MacEwan Press.

Bellefeuille, G., \& Ricks, F. (2010). Relational inquiry: A child and youth care approach to research. Children and Youth Services, 32, 1235-1241.

Creswell, J. W. (2013). Qualitative inquiry and research design: Choosing among five approaches (3rd ed.). Thousand Oaks, CA: Sage.

Eckroth-Bucher, M. (2010) Self-awareness: A review and analysis of a basic nursing concept. Advances in Nursing Science, 33(4), 297-309.

Fewster, G. (1990). Being in child care: A journey into self. New York, NY: Haworth.

Garfat, T. (2008). The inter-personal in-between: An exploration of relational child and youth care practice. In G. Bellefeuille \& F. Ricks (Eds.), Standing on the precipice: Inquiry into the creative potential of child and youth care practice (pp 7-34). Edmonton, AB: MacEwan Press.

Hannula, M., Suoranta, J., \& Vandén, T. (2005). Artistic research: Theory, method and practices. Helsinki, FI: Academy of Fine Arts.

Harrison, M., Dunbar, D., Ratmansky, L., Boyd, K., \& Lopatto, D. (2011). Classroom-based science research at the introductory level: Changes in career choices and attitude. CBE Life Sciences Education, 10(3), 279-286.

Krueger, M. (2000). Central themes in child and youth care practice. CYC-OnLine, 12(January). Retrieve from http://www.cyc-net.org/ cyc-online/cycol-0100-krueger.html

Krueger, R. A. (1994). Focus groups: A practical guide for applied research (2nd ed.). Thousand Oaks, CA: Sage. Leavy, P. (2009). Method meets art: Arts-based research practice. New York, NY: Guilford Press.

Maier, H. W. (1979). The core of care: Essential ingredients for the development of children at home and away from home. Child Care Quarterly, 8(3), 161-173.

McNiff, S. (2007). Arts-based research. In J. G. Knowles \& A. L. Cole (Eds.), Handbook of the arts in qualitative research (pp. 29-40). Thousand Oaks, CA: AltaMira Press.

Patton, M. Q. (2002). Qualitative research and evaluation methods (3rd ed.). Thousand Oaks, CA: Sage.

Ricks, F. (1989). Self-awareness model for training and application in child and youth care. Journal of Child and Youth Care, 4(1), 33-41.

Ricks, F. (2001). Without the self there is no other. CYC Online, 27. Retrieved from: http://www.cyc-net.org/cyconline/cycol-0401-ricks.html

Ricks, F. (2003). Relatedness in relationships: It's about being. Relational Child \& Youth Care Practice, 16(3), 7077.

Schwandt, T. A. (2000). Three epistemological stances for qualitative inquiry: Interpretivism, hermeneutics, and social constructionism. In N.K. Denzin \& Y.S. Lincoln (Eds.), Handbook of qualitative research (2nd ed., pp. 189214). Thousand Oaks, CA.: Sage.

Stewart, D. W., Shamdasani, P. N., \& Rook, D. W. (2007). Focus groups: Theory and practice (2nd ed.). Thousand Oaks, CA: Sage. 